\title{
Exhaled nitric oxide in endotoxin-exposed adults: effect modification by smoking and atopy
}

L A M Smit, D Heederik, G Doekes and I M Wouters

Occup. Environ. Med. 2009;66;251-255; originally published online 5 Dec 2008; doi:10.1136/oem.2008.042465

Updated information and services can be found at:

http://oem.bmj.com/cgi/content/full/66/4/251

These include:

References This article cites 36 articles, 19 of which can be accessed free at: http://oem.bmj.com/cgi/content/full/66/4/251\#BIBL

Rapid responses You can respond to this article at: http://oem.bmj.com/cgi/eletter-submit/66/4/251

Email alerting Receive free email alerts when new articles cite this article - sign up in the box at service the top right corner of the article

Notes

To order reprints of this article go to:

http://journals.bmj.com/cgi/reprintform

To subscribe to Occupational and Environmental Medicine go to:

http://journals.bmj.com/subscriptions/ 


\title{
Exhaled nitric oxide in endotoxin-exposed adults: effect modification by smoking and atopy
}

\author{
L A M Smit, D Heederik, G Doekes, I M Wouters
}

Institute for Risk Assessment Sciences, Division of Environmental Epidemiology, Utrecht University, Utrecht, The Netherlands

Correspondence to: Lidwien Smit, Institute for Risk Assessment Sciences, Division of Environmental Epidemiology, P0 Box 80178, 3508 TD Utrecht,

The Netherlands:

L.A.Smit@uu.nl

Accepted 19 September 2008 Published Online First

5 December 2008

\begin{abstract}
Objectives: Occupational exposure to endotoxin is associated with non-allergic asthma and other airway inflammatory reactions. Little is known about the role of mucosal nitric oxide (NO) production in endotoxin-induced airway inflammation. The objective was to explore exposure-response relationships between occupational endotoxin exposure and fractional concentrations of exhaled NO ( $\left.\mathrm{FE}_{\mathrm{NO}}\right)$ and study the role of $\mathrm{FE}_{\mathrm{NO}}$ as an intermediate factor in the relationship between endotoxin exposure and asthma-like symptoms.
\end{abstract}

Methods: $\mathrm{FE}_{\mathrm{NO}}$ was measured online in 425 farmers and agricultural processing workers. For each participant (cumulative) endotoxin level was modelled on the basis of 249 personal measurements and job history. Atopy was assessed as specific serum IgE to common inhalant allergens, and other health data and personal characteristics by standardised questionnaires.

Results: A significant positive exposure-response relationship was found between endotoxin and $\mathrm{FE}_{\mathrm{NO}}$, but only in non-atopic, non-smoking subjects $(p=0.001)$. $\mathrm{FE}_{\mathrm{NO}}$ was significantly associated with current wheeze and other asthma-like symptoms irrespective of atopy and current smoking. Associations between endotoxin exposure and symptoms changed slightly after adjusting for $\mathrm{FE}_{\mathrm{NO}}$.

Conclusions: A positive association was found between occupational endotoxin exposure and exhaled nitric oxide in non-smoking, non-atopic adults. Increased $\mathrm{FE}_{\mathrm{NO}}$ was associated with asthma-like symptoms, but the role of $\mathrm{FE}_{\mathrm{NO}}$ as an intermediate factor between endotoxin exposure and airway symptoms appears to be limited.

Epidemiological studies in occupational environments have shown associations between endotoxin exposure and health effects such as respiratory symptoms, non-allergic asthma, accelerated lung function decline, and organic dust toxic syndrome (ODTS) ${ }^{1-4}$ Inflammatory responses to inhaled endotoxin are characterised by increased levels of neutrophils and proinflammatory cytokines as shown in nasal lavage, induced sputum and bronchoalveolar lavage studies. ${ }^{5-8}$ Animal models and in vitro cell studies have demonstrated that endotoxins can induce the expression of nitric oxide (NO) synthase which may result in increased levels of the fractional concentration of exhaled $\mathrm{NO}\left(\mathrm{FE}_{\mathrm{NO}}\right) .^{9} 10$

Endotoxin inhalation challenge in human experimental studies caused an acute and temporary increase in $\mathrm{FE}_{\mathrm{NO}}$ in patients with asthma but not in healthy volunteers. ${ }^{11}{ }^{12}$

Exhaled NO is a non-invasive and reproducible indicator of airway inflammation, and chronically increased $\mathrm{FE}_{\mathrm{NO}}$ has been associated with respiratory disease and atopy in both children and adults. ${ }^{13-18} \mathrm{~A}$ limited number of studies have measured exhaled $\mathrm{NO}$ as a marker of airway inflammation in occupational populations. ${ }^{19}$ Some of these studies involved populations exposed to occupational sensitisers and resulted in conflicting evidence regarding the usefulness of exhaled $\mathrm{NO}$ in relation to occupational asthma. ${ }^{1920} \mathrm{~A}$ few studies have reported $\mathrm{FE}_{\mathrm{NO}}$ measurements in subjects exposed to mixed bioaerosols and ammonia in pig confinement buildings. Von Essen et a ${ }^{21}$ observed a small elevation in mean exhaled NO in swine confinement workers compared with urban controls. Elevated $\mathrm{FE}_{\mathrm{NO}}$ has also been demonstrated in previously unexposed, healthy volunteers, $5 \mathrm{~h}$ after exposure in a pig confinement building. ${ }^{22}$ However, no effect of acute bioaerosol exposure on $\mathrm{FE}_{\mathrm{NO}}$ was found in three other studies among healthy volunteers or subjects with asthma. ${ }^{23-25}$

The current authors recently reported significant associations between endotoxin exposure and respiratory symptoms such as wheeze, shortness of breath and cough in a large adult population occupationally exposed to high levels of endotoxin. ${ }^{1}$ In the present study, exposure-response relationships between endotoxin exposure and $\mathrm{FE}_{\mathrm{NO}}$ as a marker of airway inflammation, and as a putative intermediate factor in the relationship between endotoxin and respiratory symptoms, were investigated in the same population.

\section{METHODS}

\section{Study population}

The study population was recruited among farmers and workers from agricultural processing industries. A detailed description of the enrolment of the study population is given elsewhere. ${ }^{1}$ In short, questionnaires including items on asthma and asthma-like symptoms of the European Community Respiratory Health Survey (ECRHS) questionnaire ${ }^{26}$ were sent to farm owners and to employees of participating agricultural processing companies. The questionnaire was completed by 525 farmers, a farm owner response rate of $61 \%$, and 376 agricultural processing workers, a response rate of $90 \%$.

A total of 358 agricultural processing workers, $95 \%$ of questionnaire responders, agreed to participate in a medical examination. Of the 525 farmers who completed the questionnaire, 340 $(65 \%)$ indicated that they would not object to being contacted for a medical examination. For logistical reasons, however, only approximately 100 farmers could be included. A random sample of 122 farmers was approached by telephone, and 96 $(79 \%)$ were able to participate on one of the 
Figure 1 Flow diagram showing recruitment of the study population.

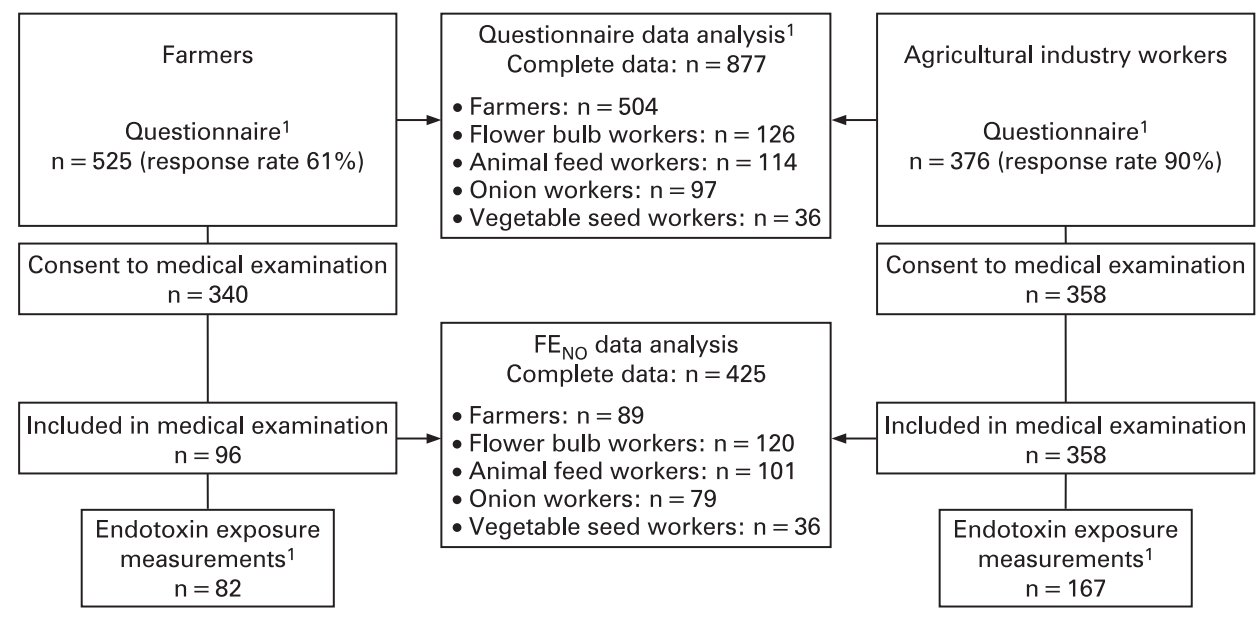

proposed dates. Data from 425 of 454 participating subjects were used because we excluded subjects who did not consent to blood sampling $(n=20)$, subjects who failed to perform an acceptable $\mathrm{FE}_{\mathrm{NO}}$ measurement $(\mathrm{n}=2)$, subjects aged $<18$ or $>65$ years $(n=4)$, and subjects who had incomplete questionnaire data $(n=3)$. An overview of the selection procedure is presented in fig 1 . The study protocol was approved by the local medical ethics committee and all participants gave written informed consent.

\section{Endotoxin exposure}

Endotoxin exposure assessment and modelling has been reported in detail earlier. ${ }^{1}$ Briefly, a job-exposure matrix was constructed using 249 personal airborne endotoxin exposure measurements. For each participant, individual (cumulative) endotoxin level was calculated by multiplying modelled exposure level (in endotoxin units $(\mathrm{EU}) / \mathrm{m}^{3}$ ) and years of exposure. Subjects had worked on average for 15.4 years (SD 11.4 years) in agriculture.

\section{FE $_{\text {No }}$ measurement}

All measurements took place on site at the beginning of the workday. Thus, $\mathrm{FE}_{\mathrm{NO}}$ was measured as an indicator of chronic inflammation rather than as an effect of acute endotoxin exposure. Measurements took place from February to mid-April, and from mid-June to December 2006. Each subject performed a single online measurement for $10 \mathrm{~s}$ at an exhalation flow rate of $50 \mathrm{ml} / \mathrm{s}$ and a pressure of $10 \mathrm{~cm} \mathrm{H}_{2} \mathrm{O}$ using a portable $\mathrm{NO}$ sampling device that measures $\mathrm{FE}_{\mathrm{NO}}$ via an electrochemical sensor (Niox Mino, Aerocrine AB, Solna, Sweden). Niox Mino was recently evaluated and a single measurement was found to be directly comparable with the arithmetic mean value of three measurements on a conventional chemiluminescence analyser. ${ }^{27} 28$ The same Niox Mino device was used for all measurements. Before testing, subjects were asked questions about smoking and caffeine intake $<1 \mathrm{~h}$ before the measurement, and having had a cold or flu or having used medication last week.

\section{Specific $\lg \mathbf{E}$}

Specific immunoglobulin E (IgE) antibodies to the common allergens house dust mite, grass pollen (mix of timothy and perennial ryegrass), cat and dog were measured by enzyme immunoassays as described previously. ${ }^{29}{ }^{30}$ Atopy was defined as serum IgE to one or more common allergens.

\section{Data analysis}

Associations between modelled cumulative endotoxin exposure and $\mathrm{FE}_{\mathrm{NO}}$, and associations between respiratory symptoms and $\mathrm{FE}_{\mathrm{NO}}$ were studied by univariate and multiple linear regression analyses, using ln-transformed $\mathrm{FE}_{\mathrm{NO}}$ and endotoxin levels. Geometric mean $\mathrm{FE}_{\mathrm{NO}}$ ratios (GMR) and $95 \%$ confidence intervals (CI) were calculated by exponentiating regression coefficients and their confidence intervals. Associations between modelled cumulative endotoxin exposure and $\mathrm{FE}_{\mathrm{NO}}$ are represented as GMR for an interquartile range of endotoxin exposure as in our previous study. ${ }^{1}$ Regression coefficients for lntransformed endotoxin exposure were first multiplied by the interquartile range of In-transformed endotoxin exposure (2.03, corresponding to a $\exp ^{2.03}=7.6$-fold increase in endotoxin exposure), and then exponentiated to obtain the GMR for an interquartile range increase in exposure. Comparison between parametric models and models including smoothed functions showed that parametric linear regression models adequately described associations between endotoxin exposure and $\mathrm{FE}_{\mathrm{NO}}$. Effect modification by current smoking and atopy was explored. Sensitivity analyses were performed by repeating statistical analyses in the subpopulation of agricultural industry workers only. Unless stated otherwise, results were adjusted for age, sex and height.

\section{RESULTS}

Geometric mean (GM) $\mathrm{FE}_{\mathrm{NO}}$ levels (ppb), 25th and 75th percentiles, and crude GM FE $\mathrm{NO}_{\mathrm{NO}}$ ratios for personal characteristics are shown in table 1. Unadjusted $\mathrm{FE}_{\mathrm{NO}}$ levels were slightly higher among workers exposed to endotoxin above the median level (17.6 vs $15.9 \mathrm{ppb} \mathrm{NO}$ ), but this difference was not statistically significant $(p=0.12)$. Male sex, height and atopy were significantly associated with increased $\mathrm{FE}_{\mathrm{NO}}$ levels. Current smoking was associated with strongly reduced levels (12.0 ppb NO in smokers vs $18.5 \mathrm{ppb} \mathrm{NO}$ in ex-smokers and $19.5 \mathrm{ppb} \mathrm{NO}$ in never smokers, $\mathrm{p}<0.001)$. Hereafter, ex-smokers and never smokers will be grouped together and referred to as non-smokers.

$\mathrm{FE}_{\mathrm{NO}}$ was associated with endotoxin exposure in nonsmoking subjects ( $p=0.02$; table 2$)$. Age, height and atopy were also independently and positively associated with $\mathrm{FE}_{\mathrm{NO}}$ levels, but only in non-smoking workers. Further analyses were limited to non-smokers. A significant exposure-response relationship was found between endotoxin exposure and $\mathrm{FE}_{\mathrm{NO}}$ in non-atopic but not in atopic subjects (fig 2). The unadjusted 
Table $1 \mathrm{GM} \mathrm{FE}_{\mathrm{NO}}$ levels (ppb) and crude GMR (95\% Cl) in 425 agricultural workers

\begin{tabular}{|c|c|c|c|c|}
\hline Predictor & n & GM & $\begin{array}{l}\text { 25th-75th } \\
\text { Percentile }\end{array}$ & GMR (95\% Cl) \\
\hline \multicolumn{5}{|l|}{ Cumulative endotoxin exposure } \\
\hline$<4117 \mathrm{EU} / \mathrm{m}^{3} \times$ year (median) & 212 & 15.9 & $10-22$ & 1 \\
\hline$\geqslant 4117 \mathrm{EU} / \mathrm{m}^{3} \times$ year & 213 & 17.6 & $12-27$ & $1.10(0.97$ to 1.25$)$ \\
\hline \multicolumn{5}{|l|}{ Sex } \\
\hline Female & 55 & 11.4 & $7-16$ & 1 \\
\hline Male & 370 & 17.7 & $12-26$ & 1.56 (1.30 to 1.87$)$ \\
\hline \multicolumn{5}{|l|}{ Age } \\
\hline$<42.3$ years (median) & 212 & 16.2 & $11-23$ & 1 \\
\hline$\geqslant 42.3$ years & 213 & 17.2 & $11-26$ & $1.06(0.94$ to 1.20$)$ \\
\hline \multicolumn{5}{|l|}{ Smoking habits } \\
\hline Non-smoker & 173 & 19.5 & $13-28$ & 1 \\
\hline Former smoker & 133 & 18.5 & $12-28$ & 0.95 (0.82 to 1.10$)$ \\
\hline Current smoker & 119 & 12.0 & 8-19 & $0.61(0.53$ to 0.71$)$ \\
\hline \multicolumn{5}{|l|}{ Height } \\
\hline$<1.79$ m (median) & 212 & 15.3 & $10-24$ & 1 \\
\hline$\geqslant 1.79 \mathrm{~m}$ & 213 & 18.2 & $12-27$ & 1.19 (1.05 to 1.35$)$ \\
\hline \multicolumn{5}{|l|}{ Atopy } \\
\hline No & 345 & 15.4 & $11-22$ & 1 \\
\hline Yes & 80 & 23.6 & $13-38$ & 1.53 (1.31 to 1.79$)$ \\
\hline
\end{tabular}

$\mathrm{GM}$, geometric mean; GMR, geometric mean $\mathrm{FE}_{\mathrm{No}}$ ratio.

GMR for non-atopic, non-smoking subjects at the 75th percentile of endotoxin exposure versus subjects at the 25th percentile was 1.15 (95\% CI 1.07 to 1.23; p<0.001). Adjustment for sex, age and height resulted in a slightly lower GMR (1.13, $95 \%$ CI 1.05 to $1.21 ; \mathrm{p}=0.001)$. The influence of caffeine intake, use of inhaled or oral corticosteroids (reported by five subjects), pollen season, and having had a cold or flu last week was also assessed in the analyses, but these variables did not change associations between endotoxin exposure and $\mathrm{FE}_{\mathrm{NO}}$. The accuracy of the regression models was further examined by removing the most influential data points (identified by Cook's distance), which slightly increased the adjusted GMR for the association between endotoxin exposure and $\mathrm{FE}_{\mathrm{NO}}$ in nonsmoking, non-atopic workers (1.15, 95\% CI 1.08 to 1.22; $p<0.001)$. Similar results were obtained when sensitivity analyses were performed by repeating analyses in the subpopulation of agricultural processing workers only (GMR 1.16, 95\% CI 1.07 to $1.25 ; \mathrm{p}<0.001)$.

In non-smoking, non-atopic workers, a statistically significant association was also found between present endotoxin exposure levels $\left(\mathrm{EU} / \mathrm{m}^{3}\right)$ and $\mathrm{FE}_{\mathrm{NO}}(\mathrm{GMR} 1.09,95 \%$ CI 1.03 to 1.17; $p=0.006)$. In a regression model that contained both present endotoxin levels $\left(\mathrm{EU} / \mathrm{m}^{3}\right)$ and years of exposure as two separate variables, the same GMR was found for present exposure level (GMR 1.09, 95\% CI 1.02 to 1.16; $p=0.007$ ), and a positive but not significant association was found between years of exposure (GMR per 10 years: 1.05, 95\% CI 0.97 to $1.13 ; p=0.21)$ and $\mathrm{FE}_{\mathrm{NO}}$. The earlier presented model with cumulative endotoxin exposure $\left(\mathrm{EU} / \mathrm{m}^{3} \times\right.$ year) was, however, the best-fitting model (log-likelihood: -200.5, vs -201.77 for the model with present exposure and -201.0 for the model with present exposure and years of exposure as two separate variables).

Current wheeze was significantly associated with $\mathrm{FE}_{\mathrm{NO}}$, irrespective of atopy and current smoking (fig 3). Adjustment for age, sex and height did not change the observed associations. Similar associations with $\mathrm{FE}_{\mathrm{NO}}$ were found for wheezing without a cold, wheezing with shortness of breath, and shortness of breath during the night, but not for cough symptoms (data not shown).

In the subgroup of non-atopic non-smokers, we studied the role of $\mathrm{FE}_{\mathrm{NO}}$ as an intermediate factor in the association between endotoxin exposure and symptoms. As shown in table 3, associations between endotoxin exposure and symptoms changed only slightly after adjusting for $\mathrm{FE}_{\mathrm{NO}}$, suggesting that exhaled $\mathrm{NO}$ is not an essential intermediate factor for endotoxin-induced respiratory symptoms.

\section{DISCUSSION}

In the present study, a significant exposure-response relationship was found between exposure to endotoxin and exhaled NO in non-smoking, non-atopic agricultural workers. Current wheeze and other respiratory symptoms were significantly associated with $\mathrm{FE}_{\mathrm{NO}}$, irrespective of atopy and current smoking. However, results suggest that exhaled $\mathrm{NO}$ has only a limited role as an intermediate factor between endotoxin exposure and respiratory symptoms.

A few studies on organic and inorganic dust and chemical exposures have reported higher $\mathrm{FE}_{\mathrm{NO}}$ levels among swine farmers, underground construction workers, aluminium potroom workers, and ozone exposed bleachery workers as compared with control groups. ${ }^{21}{ }^{31-33}$ Differences in $\mathrm{FE}_{\mathrm{NO}}$ levels between exposed and unexposed groups were usually relatively small (between 15\% and 63\% higher in exposed subjects) but may indicate subclinical inflammation due to pro-inflammatory
Figure 2 Linear regression plots with pointwise $95 \%$ confidence intervals representing associations between modelled cumulative endotoxin exposure and $\mathrm{FE}_{\mathrm{NO}}$ in 242 non-smoking, non-atopic subjects (circles; $\beta$ coefficient $(\mathrm{SE})=0.068(0.019))$ and 64 nonsmoking, atopic subjects (triangles; $\beta$ coefficient $(\mathrm{SE})=-0.003(0.04))$.

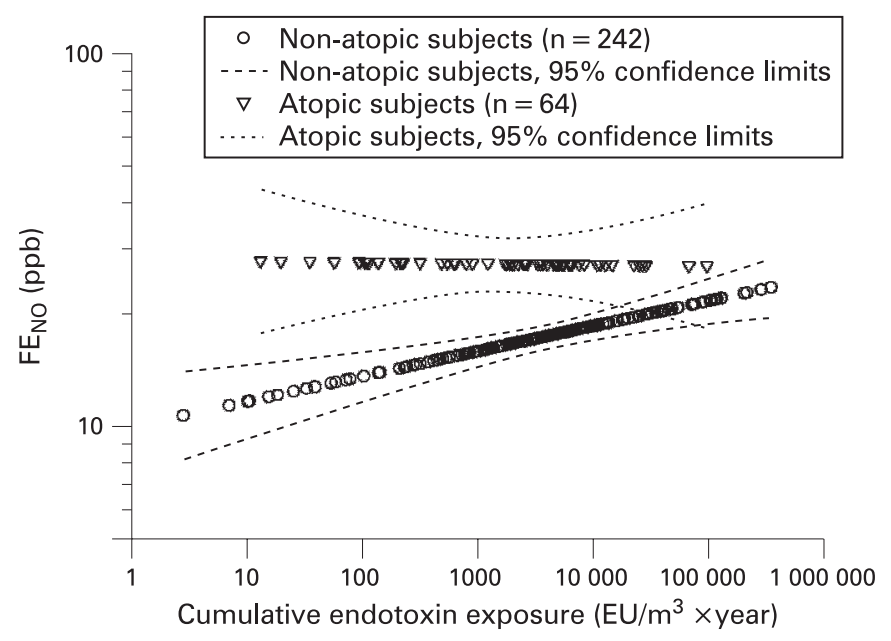


Table 2 Adjusted GMR for $\mathrm{FE}_{\mathrm{NO}}$ in 425 agricultural workers, stratified by current smoking

\begin{tabular}{|c|c|c|}
\hline Predictor & $\begin{array}{l}\text { Non-smokers } \\
(\mathrm{n}=306) \\
\text { GMR }(95 \% \mathrm{CI}) \dagger\end{array}$ & $\begin{array}{l}\text { Current smokers } \\
(\mathrm{n}=119) \\
\text { GMR }(95 \% \mathrm{Cl}) \dagger\end{array}$ \\
\hline Cumulative endotoxin exposure $\$$ & $1.08(1.01 \text { to } 1.16)^{*}$ & $0.99(0.88$ to 1.11$)$ \\
\hline Male sex & $1.21(0.95$ to 1.53$)$ & $1.26(0.87$ to 1.84$)$ \\
\hline Age (per 10 years) & $1.11(1.03 \text { to } 1.19)^{*}$ & $0.99(0.90$ to 1.10$)$ \\
\hline Height (per $10 \mathrm{~cm}$ ) & $1.12(1.01 \text { to } 1.24)^{*}$ & $1.11(0.97$ to 1.28$)$ \\
\hline Atopy & $1.64(1.39 \text { to } 1.93)^{* *}$ & $1.08(0.79$ to 1.49$)$ \\
\hline
\end{tabular}

exposures in the environment. However, within these populations no dose-response relationships with measured exposures were established. In the present study, measured endotoxin exposure data were available, and a high contrast in individual exposure levels was obtained by including workers from different agricultural processing industries. ${ }^{1}$ Moreover, the large size of the study population allowed for control for potential confounders or effect modifying factors like smoking and atopy, and the results showed that effect modification by smoking and atopy indeed had a major impact on the dose-response relationships. Still, results showed that even in the subgroup with the strongest association, average exhaled $\mathrm{NO}$ levels increased only twofold over a range of five orders of magnitude of cumulative endotoxin exposure. This may explain why in many other studies with less pronounced exposure gradients and/or no adequate adjustments, an exposure-response relationship will easily be missed.

Exposure-response relationships between endotoxin and $\mathrm{FE}_{\mathrm{NO}}$ were observed only when analyses were limited to nonsmokers. It is well-known that smokers exhibit strongly reduced $\mathrm{FE}_{\mathrm{NO}}{ }^{34}$ and as a result the usefulness of exhaled $\mathrm{NO}$ as a tool to assess airway inflammation among smokers appears to be questionable. Therefore, in the present study and in previous studies in occupational settings, smokers were excluded or results were stratified by current smoking. ${ }^{21} 2231-333536$ In addition to the inhibitory effect of current smoking on $\mathrm{FE}_{\mathrm{NO}}$ values and on endotoxin-associated enhanced $\mathrm{FE}_{\mathrm{NO}}$, we also found that endotoxin exposure was only associated with increased $\mathrm{FE}_{\mathrm{NO}}$ in non-smoking subjects without sensitisation to common allergens. Avoidance of high endotoxin exposure by atopic workers with increased $\mathrm{FE}_{\mathrm{NO}}$ could have obscured an underlying exposure-response relationship. However, wheezing was significantly associated with endotoxin exposure in atopic workers (OR 2.08, 95\% CI 1.09 to 3.97), which argues against a strong effect of health-based selection. Instead, one could speculate that endotoxin exposure does not further increase the already elevated $\mathrm{FE}_{\mathrm{NO}}$ values among chronically exposed atopic subjects.

An acute but transient increase in exhaled $\mathrm{NO}$ after a single endotoxin provocation has been observed in volunteers with asthma but not in healthy subjects. ${ }^{11}{ }^{12}$ However, results of the present study in long term exposed subjects and observations in naive individuals after acute endotoxin exposure are difficult to compare. In the present study, the vast majority of subjects (95\%) had been working in agriculture for more than 1 year, and exhaled NO was measured before the workday. The relationship between cumulative endotoxin exposure (EU/ $\mathrm{m}^{3}$ xyear) and $\mathrm{FE}_{\mathrm{NO}}$ was stronger than the relationship between

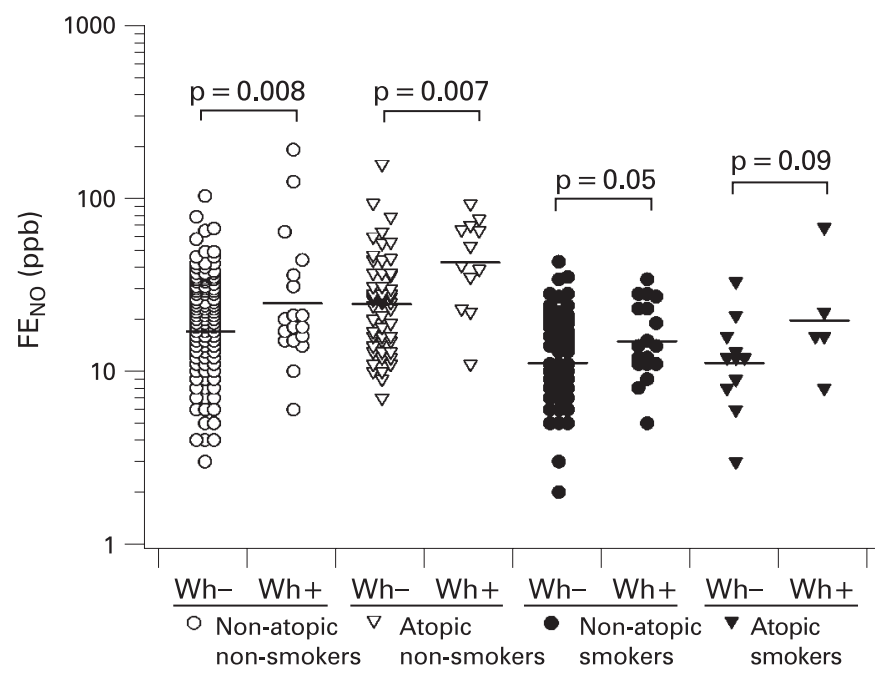

Figure $3 \mathrm{FE}_{\mathrm{NO}}$ values in non-atopic non-smokers, atopic non-smokers, non-atopic smokers, and atopic smokers for non-wheezers and current wheezers (Wh- and $\mathrm{Wh}+$ ). Horizontal lines represent geometric means. Geometric mean $\mathrm{FE}_{\mathrm{NO}}$ ratios for subjects reporting wheeze versus nonwheezing subjects were 1.46, 1.73, 1.32 and 1.78 for non-atopic nonsmokers, atopic non-smokers, non-atopic smokers and atopic smokers, respectively.

present endotoxin levels $\left(\mathrm{EU} / \mathrm{m}^{3}\right)$ and $\mathrm{FE}_{\mathrm{NO}}$. Results of the present study thus suggest that elevated exhaled $\mathrm{NO}$ in endotoxin exposed workers may represent mild chronic inflammation rather than an acute effect of current endotoxin exposure. However, elucidation of the underlying mechanisms of chronically increased exhaled NO levels would help interpretation of the biological relevance of the present epidemiological observations.

In all subgroups, self-reported wheeze and other asthma-like symptoms were associated with increased $\mathrm{FE}_{\mathrm{NO}}$ levels. In a cross-section of agricultural workers, one would expect that current wheeze (wheeze at any time during the last 12 months) represents relatively mild airway obstruction. It is likely that many subjects were not experiencing symptoms during the week before $\mathrm{FE}_{\mathrm{NO}}$ measurements, which is supported by the fact that only five subjects reported the use of inhaled corticosteroids during the last week. Therefore, subjects reporting wheeze are likely to exhibit increased but relatively stable exhaled NO values as has been shown in patients with mild asthma, who showed no diurnal or day-to-day variation in $\mathrm{FE}_{\mathrm{NO}}{ }^{18}$. Whether $\mathrm{FE}_{\mathrm{NO}}$ acts as an intermediate factor in the relationship between endotoxin and asthma-like symptoms was only investigated in non-atopic non-smokers, since the strong relationships between exhaled NO, smoking and atopy would

Table 3 Associations between cumulative endotoxin exposure and symptoms in non-smoking, non-atopic agricultural workers $(n=242)$, with and without adjustment for $\mathrm{FE}_{\mathrm{NO}}$

\begin{tabular}{lll}
\hline & $\begin{array}{l}\text { OR (95\% Cl), } \\
\text { model 1* }\end{array}$ & $\begin{array}{l}\text { OR (95\% CI), } \\
\text { model 2* }\end{array}$ \\
\hline Wheezing & $1.45(0.85$ to 2.48$)$ & $1.34(0.77$ to 2.34$)$ \\
Wheezing with shortness of breath & $1.60(0.89$ to 2.86$)$ & $1.50(0.82$ to 2.73$)$ \\
Wheezing without a cold & $2.39(1.08$ to 5.31$)$ & $2.27(1.02$ to 5.06$)$ \\
Awakened due to shortness of breath & $2.26(0.82$ to 6.27$)$ & 2.16 (0.79 to 5.94$)$
\end{tabular}

${ }^{*}$ Odds ratio $(\mathrm{OR})$ for an interquartile range $\left(\exp ^{2.03}=\right.$ factor 7.6$)$ increase in endotoxin exposure $\left(\mathrm{EU} / \mathrm{m}^{3} \times\right.$ year $)$.

Model 1, adjusted for sex and age; model 2, adjusted for exhaled NO, sex and age. 


\section{Main messages}

- Occupational endotoxin exposure is associated with exhaled nitric oxide in a dose-dependent manner, but only in nonsmoking, non-atopic subjects.

- Increased exhaled nitric oxide is associated with current wheeze and other asthma-like symptoms in endotoxinexposed agricultural workers.

\section{Policy implications}

Exhaled nitric oxide may be a useful tool in epidemiological studies investigating the health effects of endotoxin exposure.

complicate further interpretation of findings in smokers and atopic subjects. Associations between endotoxin exposure and symptoms decreased marginally after correction for $\mathrm{FE}_{\mathrm{NO}}$, suggesting that exhaled $\mathrm{NO}$ is not of major importance as an intermediate factor between endotoxin exposure and associated respiratory symptoms.

Although we have shown that measuring $\mathrm{FE}_{\mathrm{NO}}$ may be a useful tool in an epidemiological survey investigating the health effects of endotoxin exposure, a question for future research in exposed workers would obviously be whether $\mathrm{FE}_{\mathrm{NO}}$ can be used to identify subjects with a higher risk of developing more severe airway inflammation. This question is difficult to answer using cross-sectional data, and a longitudinal study would be needed to investigate the potential of $\mathrm{FE}_{\mathrm{NO}}$ for predicting which workers would be at risk of occupational lung disease. Another potential of the use of exhaled $\mathrm{NO}$ in an occupational setting was demonstrated recently by Dressel et $a l^{20}$ who measured exhaled NO measurements before and after an educational intervention programme for farmers with occupational asthma, showing the efficacy of preventive measures.

In conclusion, the present study was the first to show a significant dose-response relationship between endotoxin exposure and exhaled $\mathrm{NO}$. Increased $\mathrm{FE}_{\mathrm{NO}}$ was associated with current wheeze and other asthma-like symptoms, but the role of $\mathrm{FE}_{\mathrm{NO}}$ as an intermediate factor between endotoxin exposure and symptoms appears to be limited.

Acknowledgements: We gratefully acknowledge Siegfried de Wind, Isabella Oosting, Willeke Munneke and Ilse van Zweden for fieldwork and Jack Spithoven for IgE analyses (Institute for Risk Assessment Sciences, Utrecht University, The Netherlands). We wish to thank all workers for participation in the study.

Funding: This study was funded by the Netherlands Asthma Foundation (grant no. 3.2.03.70).

Competing interests: None.

Ethics approval: The study protocol was approved by the local medical ethics committee.

\section{REFERENCES}

1. Smit LA, Heederik D, Doekes G, et al. Exposure-response analysis of allergy and respiratory symptoms in endotoxin-exposed adults. Eur Respir J 2008;31:1241-8.

2. Vogelzang PF, van der Gulden JW, Folgering $\mathrm{H}$, et al. Endotoxin exposure as a major determinant of lung function decline in pig farmers. Am J Respir Crit Care Med 1998;157:15-18.

3. Douwes J, Thorne P, Pearce N, et al. Bioaerosol health effects and exposure assessment: progress and prospects. Ann Occup Hyg 2003:47:187-200.

4. Eduard W, Douwes J, Omenaas $\mathrm{E}$, et al. Do farming exposures cause or prevent asthma? Results from a study of adult Norwegian farmers. Thorax 2004;59:381-6.
5. Larsson BM, Palmberg L, Malmberg P0, et al. Effect of exposure to swine dust on levels of IL-8 in airway lavage fluid. Thorax 1997;52:638-42.

6. Heldal KK, Halstensen AS, Thorn J, et al. Airway inflammation in waste handlers exposed to bioaerosols assessed by induced sputum. Eur Respir J 2003:21:641-5.

7. Wang Z, Larsson K, Palmberg L, et al. Inhalation of swine dust induces cytokine release in the upper and lower airways. Eur Respir J 1997:10:381-7.

8. Wouters IM, Hilhorst SK, Kleppe P, et al. Upper airway inflammation and respiratory symptoms in domestic waste collectors. Occup Environ Med 2002;59:106-12.

9. Moncada S, Palmer RM, Higgs EA. Nitric oxide: physiology, pathophysiology, and pharmacology. Pharmacol Rev 1991;43:109-42.

10. Birrell MA, McCluskie K, Hardaker $\mathrm{E}$, et al. Utility of exhaled nitric oxide as a noninvasive biomarker of lung inflammation in a disease model. Eur Respir $\mathrm{J}$ 2006;28:1236-44.

11. Kitz R, Rose MA, Borgmann A, et al. Systemic and bronchial inflammation following LPS inhalation in asthmatic and healthy subjects. J Endotoxin Res 2006;12:367-74.

12. Kitz R, Rose MA, Placzek K et al. LPS inhalation challenge: a new tool to characterize the inflammatory response in humans. Med Microbiol Immunol 2008;197:13-19.

13. Brussee JE, Smit HA, Kerkhof M, et al. Exhaled nitric oxide in 4-year-old children: relationship with asthma and atopy. Eur Respir J 2005;25:455-61.

14. Kharitonov SA, Yates D, Robbins RA, et al. Increased nitric oxide in exhaled air of asthmatic patients. Lancet 1994;343:133-35.

15. Olin AC, Rosengren A, Thelle DS, et al. Height, age, and atopy are associated with fraction of exhaled nitric oxide in a large adult general population sample. Chest 2006;130:1319-25

16. Travers J, Marsh $\mathbf{S}$, Aldington $\mathrm{S}$, et al. Reference ranges for exhaled nitric oxide derived from a random community survey of adults. Am J Respir Crit Care Med 2007; 176:238-42.

17. Pijnenburg MW, De Jongste JC. Exhaled nitric oxide in childhood asthma: a review. Clin Exp Allergy 2008;38:246-59.

18. Kharitonov SA, Gonio F, Kelly C, et al. Reproducibility of exhaled nitric oxide measurements in healthy and asthmatic adults and children. Eur Respir $J$ 2003:21:433-8.

19. Lemiere C. Induced sputum and exhaled nitric oxide as noninvasive markers of airway inflammation from work exposures. Curr Opin Allergy Clin Immunol 2007; 7:133-7.

20. Dressel H, Gross C, de la Motte D, et al. Educational intervention decreases exhaled nitric oxide in farmers with occupational asthma. Eur Respir J 2007;30:545-8.

21. Von Essen SG, Scheppers LA, Robbins RA, et al. Respiratory tract inflammation in swine confinement workers studied using induced sputum and exhaled nitric oxide. J Toxicol Clin Toxicol 1998;36:557-65.

22. Sundblad BM, Larsson BM, Palmberg L, et al. Exhaled nitric oxide and bronchial responsiveness in healthy subjects exposed to organic dust. Eur Respir $\mathrm{J}$ 2002;20:426-31.

23. Kolbeck KG, Ehnhage A, Juto JE, et al. Airway reactivity and exhaled NO following swine dust exposure in healthy volunteers. Respir Med 2000;94:1065-72.

24. Sundblad BM, Sahlander K, Ek A, et al. Effect of respirators equipped with particle or particle-and-gas filters during exposure in a pig confinement building. Scand J Work Environ Health 2006;32:145-53.

25. Sigurdarson ST, O'Shaughnessy PT, Watt JA, et al. Experimental human exposure to inhaled grain dust and ammonia: towards a model of concentrated animal feeding operations. Am J Ind Med 2004;46:345-8.

26. Burney PG, Luczynska C, Chinn S, et al. The European Community Respiratory Health Survey. Eur Respir J 1994;7:954-60.

27. Menzies D, Nair A, Lipworth BJ. Portable exhaled nitric oxide measurement: comparison with the "gold standard" technique. Chest 2007:131:410-14.

28. Chen W, Purohit A, Barnig C, et al. Niox and Niox Mino: comparison of exhaled NO in grass pollen allergic adult volunteers. Allergy 2007;62:571-72.

29. Doekes G, Douwes J, Wouters I, et al. Enzyme immunoassays for total and allergen specific IgE in population studies. Occup Environ Med 1996;53:63-70.

30. Portengen $\mathbf{L}$, Preller $\mathrm{L}$, Tielen $\mathrm{M}$, et al. Endotoxin exposure and atopic sensitization in adult pig farmers. J Allergy Clin Immunol 2005;115:797-802.

31. Ulvestad B, Lund MB, Bakke B, et al. Gas and dust exposure in underground construction is associated with signs of airway inflammation. Eur Respir $\mathrm{J}$ 2001;17:416-21.

32. Lund MB, Oksne PI, Hamre R, et al. Increased nitric oxide in exhaled air: an early marker of asthma in non-smoking aluminium potroom workers? Occup Environ Med 2000; $57: 274-8$

33. Olin AC, Andersson E, Andersson M, et al. Prevalence of asthma and exhaled nitric oxide are increased in bleachery workers exposed to ozone. Eur Respir $\mathrm{J}$ 2004;23:87-92.

34. Malinovschi A, Janson C, Holmkvist T, et al. Effect of smoking on exhaled nitric oxide and flow-independent nitric oxide exchange parameters. Eur Respir $J$ 2006;28:339-45.

35. Akpinar-Elci M, Stemple KJ, Elci OC, et al. Exhaled nitric oxide measurement in workers in a microwave popcorn production plant. Int J Occup Environ Health 2006;12:106-10.

36. Olin AC, Bake B, Toren K. Fraction of exhaled nitric oxide at $50 \mathrm{~mL} / \mathrm{s}$ : reference values for adult lifelong never-smokers. Chest 2007;131:1852-6. 